\title{
STATIC PUSHOVER BEHAVIOUR OF FIXED AND HINGED RCC PORTAL FRAMES
}

\author{
V. G. Kondekar ${ }^{1 *}$, A. A. Mehta ${ }^{2}$ \\ ${ }^{1 *}$ Corresponding author, ${ }^{2}$ Assistant Professor, Department of Civil Engineering, Guru Nanak Institute of Technology, \\ Nagpur.Phone: 7387721252, E-mail: vijaykondekar@rediffmail.com \\ ${ }^{2}$ Assistant Professor, Department of Civil Engineering, Shri Ramdeobaba College of Engineering and Management, \\ Nagpur. E-mail: ashishmehta1234.ngp@gmail.com
}

\begin{abstract}
The RCC building frames are usually analyzed, designed and constructed with fixed supports. It is known that the damage to the structures during earthquakes depends on the mass and material of the structure, its type and damping, ductility and energy dissipation capacity. The induced seismic forces can be reduced by enhancing the ductility and the energy dissipation capacity of a structure, lowering probability of its failure or collapse. In this regard, this study aimed at comparing the performances of a fix supported single storey single bay RCC portal frame to that with hinged supports. Two scaled down model portal frames were casted having the same geometrical properties with M20 concrete and Fe 250 reinforcement. The hinges were designed as Mesnager hinges transmitting the thrust and shearing force, and permitting greater rotation. Static Pushover analyses of both these portal frames were performed. The portal was subjected to gravity loading and a continuously increasing lateral load. Their load-displacement responses, rotation capacities and the cracking patterns were observed and recorded. The comparisons showed the improved ductility and energy dissipation capacity of the frame with hinged supports.
\end{abstract}

Keywords: static pushover, portal frame, hinge, ductility ****

\section{INTRODUCTION}

The RCC building frames are analyzed, designed and constructed usually with support conditions taken as fixed. The transfer of stresses from the beam to the column results in rotational movement at the foundation, which can be overcome by the introduction of a hinge joint. A hinge is a type of bearing that connects two solid objects, typically allowing only a limited angle of rotation between them. The hinges are included to reduce or eliminate the transfer of bending stresses between structural components, typically in an effort to reduce sensitivity to earthquakes. It can resist both vertical and horizontal forces but not a moment. It allows the structural member to rotate, but not to translate in any direction. Hinges may be made of flexible material or of moving components and RCC hinges are not commonly used.

This study is intended to understand the effect of hinges on the structural behaviour of portal frame subjected to lateral load. A portal frame is a rigid frame consisting of a horizontal beam resting on two columns with monolithic joints at the junction of beam and columns. Because of these strong and rigid joints, some of the bending moment in the beam is transferred to the columns and the bending moment in the beam reduces. Thus, the size of the beam can be reduced or the span can be increased for the same size. This makes a portal frame an efficient construction technique used for wide span buildings.
Mashaly ${ }^{1}$ suggested static pushover analysis as a practical procedure to assess the deformability and the damage vulnerability of existing and newly designed frames without the need to perform a complex dynamic analysis. It gives an insight into the integrity and the ductility characteristics of the structural system. Dubey and Kute ${ }^{2}$ studied a laterally loaded, braced and partially in-filled single-bay, singlestory RC frames. For the experimental setup, the RC portal frame with a welded base plate was rigidly bolted to the supporting girder providing fixity as base. The portal frame had columns of $60 \mathrm{~mm} \times 100 \mathrm{~mm}$ and beam of $100 \mathrm{~mm} \times$ $100 \mathrm{~mm}$. Kilar and Fajfar ${ }^{3}$ also suggested a simple method for the nonlinear static analysis of complex building structures subjected to monotonically increasing horizontal loading (push-over analysis).

\section{METHODOLOGY}

Two scaled down model portal frames were casted having the same geometrical properties with c/c span of beam as $900 \mathrm{~mm}$ and height of columns as $900 \mathrm{~mm}$, structural layout in elevation is shown in Figure 1. The overall sizes of beam and columns casted were $(75 \mathrm{~mm} \times 90 \mathrm{~mm})$ and $(75 \mathrm{~mm} \times$ $75 \mathrm{~mm}$ ) respectively. The M20 concrete grade was designed as per IS code procedure $e^{4,5}$ and was used for casting of the frame. The mean compressive strength of concrete mix cubes was observed to be $22.33 \mathrm{~N} / \mathrm{mm}^{2}$, tested after 28 days. The value of slump was $30 \mathrm{~mm}$ for the fresh concrete. The reinforcement bars of mild steel bars of $4 \mathrm{~mm}$ diameter, Fe250 were used, in order to cater for the reduced dimensions of the beam and column sections. 


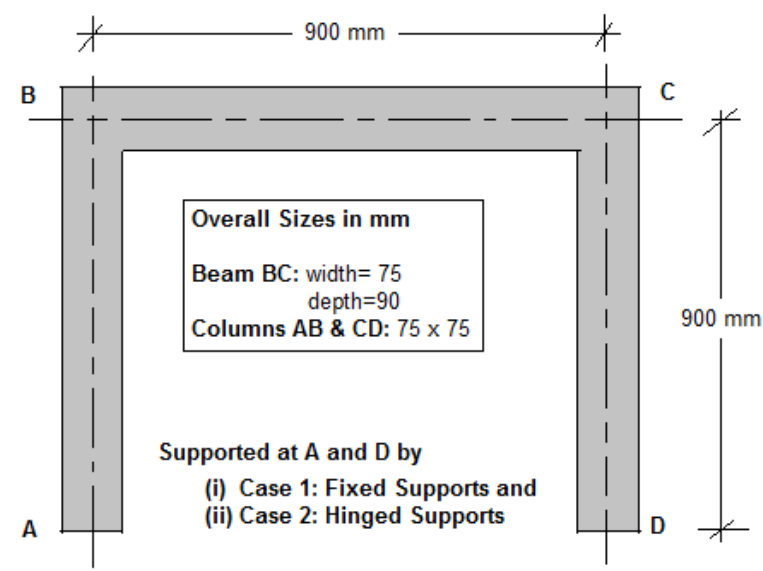

Fig. 1-Structural layout and dimensions of portal frame: elevation

The hinges were designed as Mesnager hinges transmitting the thrust and shearing force, and permitting greater rotation. The reinforcement details of the beam, columns with fixed \& hinged supports and hinge are shown in Figure 2.

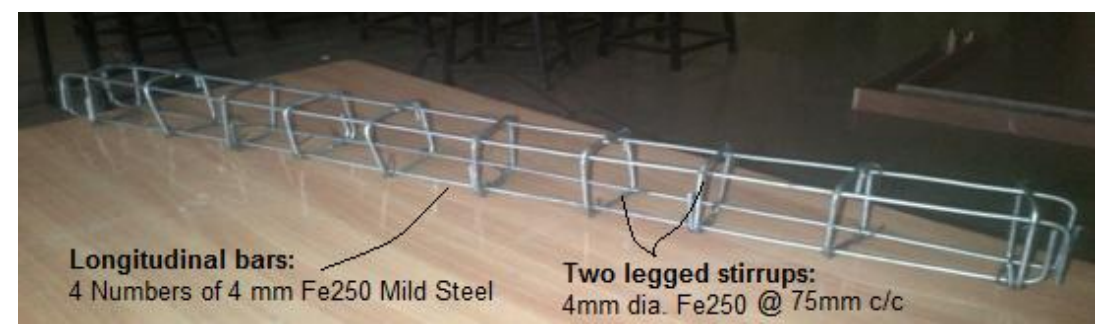

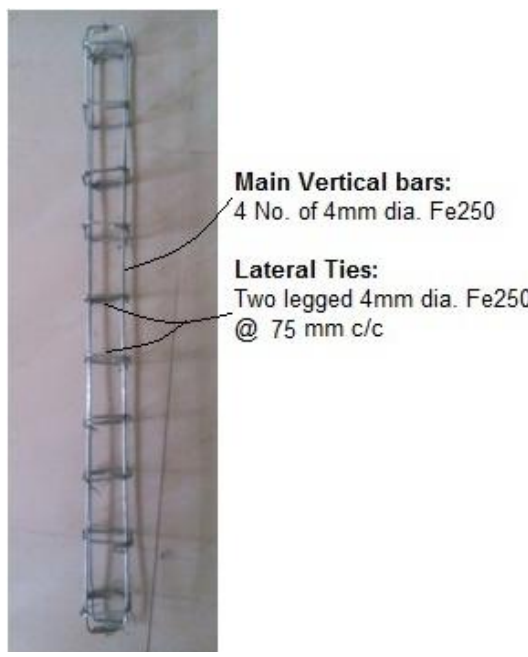

(b): $R / f$ details of column with fixed support (a): R/f details of beam

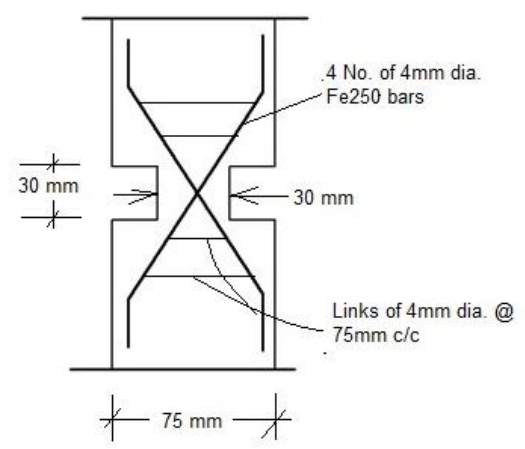

(c): $R / f$ details of Mesnager hinge

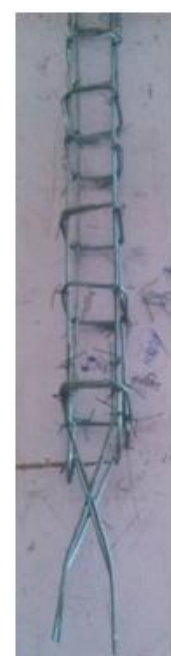

(d): R/f details of column with hinged support, bars same as (b)

Fig. 2: Reinforcement details of components of portal frame

Static Pushover analyses of both these portal frames were performed. The portal was subjected to gravity loading and a continuously increasing lateral load. Their load-displacement responses, rotation behaviour and the cracking patterns were observed and recorded.

\section{CASTING OF PORTAL FRAMES}

The formwork was properly assembled, the reinforcement cage once for portal frame with fixed supports and other for portal frame with hinged supports were placed in place properly. The concreting of frame was done with careful tamping to avoid segregation and honeycombing of the concrete. Curing is the process of controlling the rate and extent of moisture loss from concrete during cement hydration. The curing was done for 14 days by sprinkling and wetting the gunny bags placed to cover the frames. 


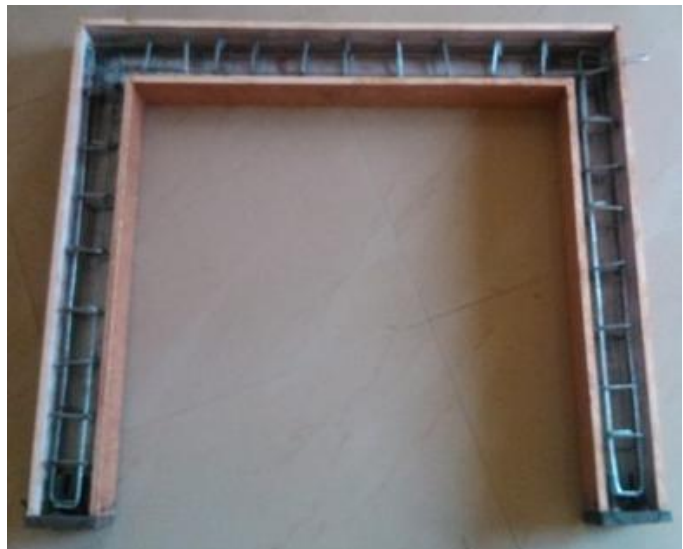

(a) Portal frame with fixed supports

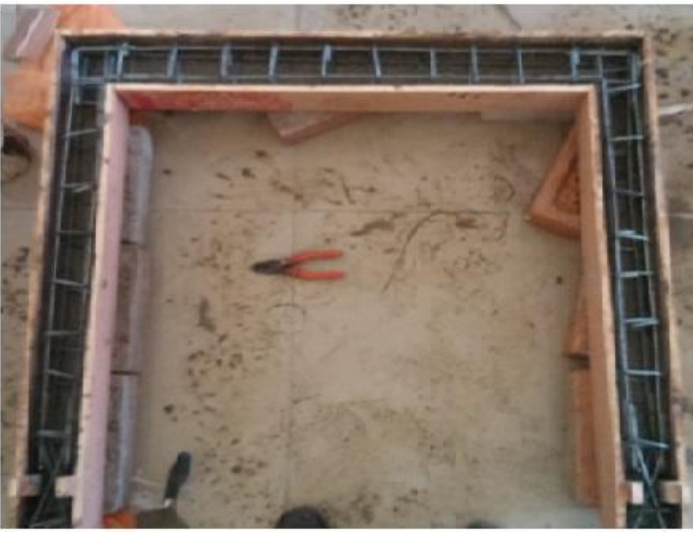

(b) Portal frame with hinged supports

Fig. 3: Casting of portal frames

\section{EXPERIMENTAL SET-UP}

Both the portal frames were subjected to increasing lateral load applied through a pulley assembly coupled to a loading frame as shown in Figure 4. The lateral push was applied at joint $\mathrm{C}$ by a wire rope connected to the hook and a clamp at $\mathrm{C}$. The lateral force was recorded from the dial gauge of the loading frame.

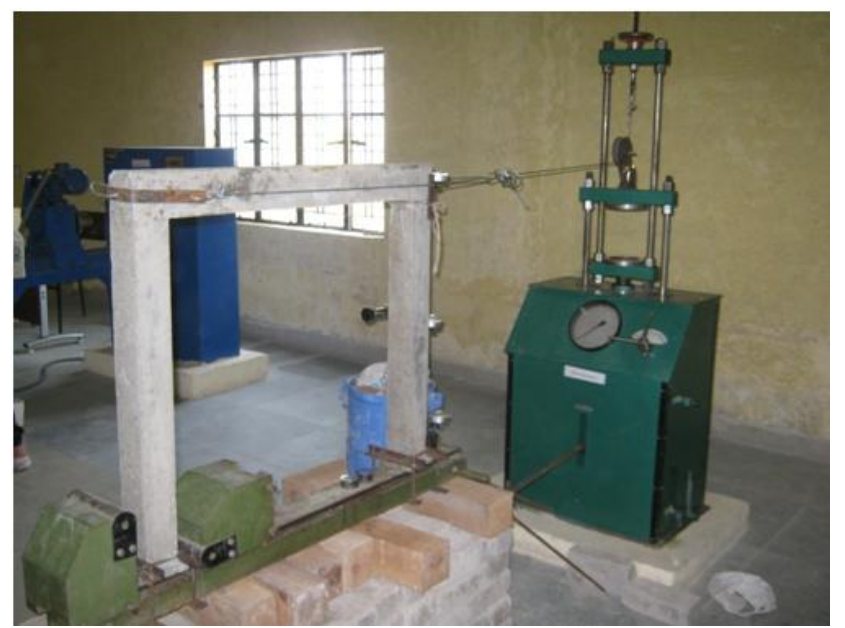

Fig. 4: Experimental set up for pushover testing of portal frames

A steel base plate was bolted during concreting of the portal frame. The fixity of the portal frame was achieved by clamping the base plate to a heavy steel girder with the help of angles and nut \& bolts as shown in Figure 5.
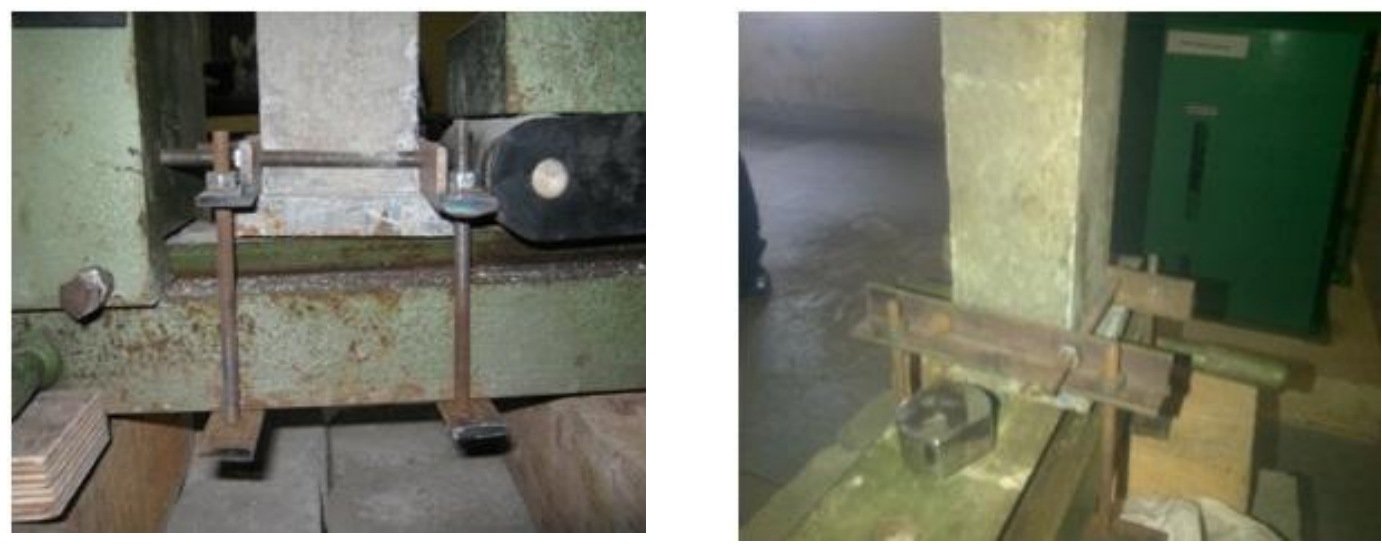

Fig. 5: Fixing the portal frame at its base 
The measurement of the deflections were recorded at three locations of column CD; one at 100mm, another at mid-level $450 \mathrm{~mm}$ and also at $900 \mathrm{~mm}$ from the base. The arrangement of the gauges for measurement of deflections is shown in Figure 6.

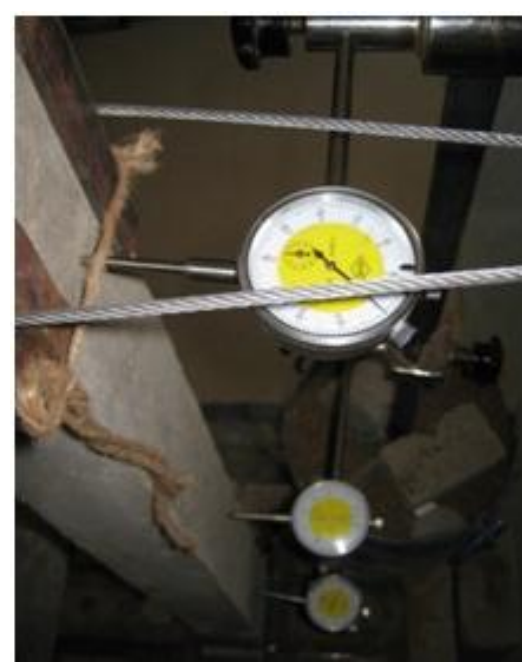

Fig. 6: Dial gauges for displacement measurement of storey drift and at intermediate levels

\section{RESULTS AND DISCUSSIONS}

The frames were subjected to pushover by increasing lateral load and their deflections were recorded at equal intervals of loading. The cracking patterns were also observed.

\section{Load versus deflection pattern and rotational capacity}

Load-deflection (storey level) response for portal frames with fixed supports and hinged supports are plotted in Figures 7 and 8. The maximum load applied was $10 \mathrm{kN}$ and almost linearly increasing patterns were observed for both the frames. The maximum storey displacement of about $14 \mathrm{~mm}$ was recorded for portal frame with fixed supports. But, the displacement increased up to 21 $\mathrm{mm}$ for the portal frame with hinged supports. This indicated the increased rotational capacity of the frame with hinges. The effectiveness of RCC hinge (Mesnager hinge) was also clearly observed.

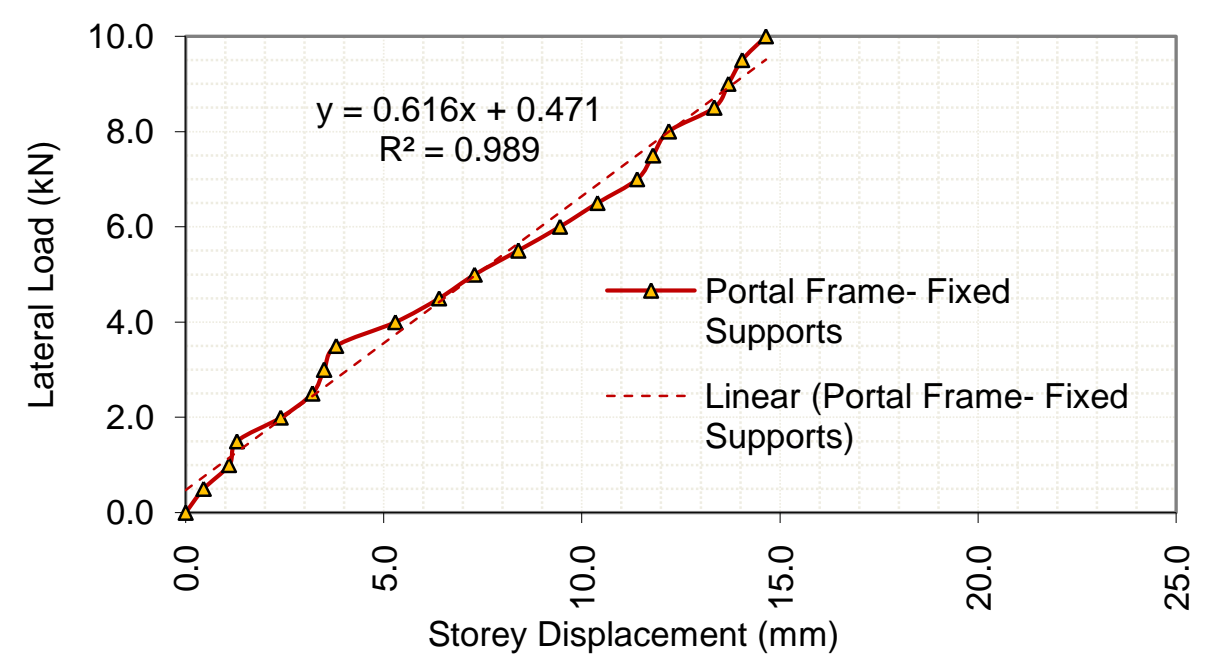

Fig. 7: Load-deflection (storey level) response for portal frames with fixed supports 


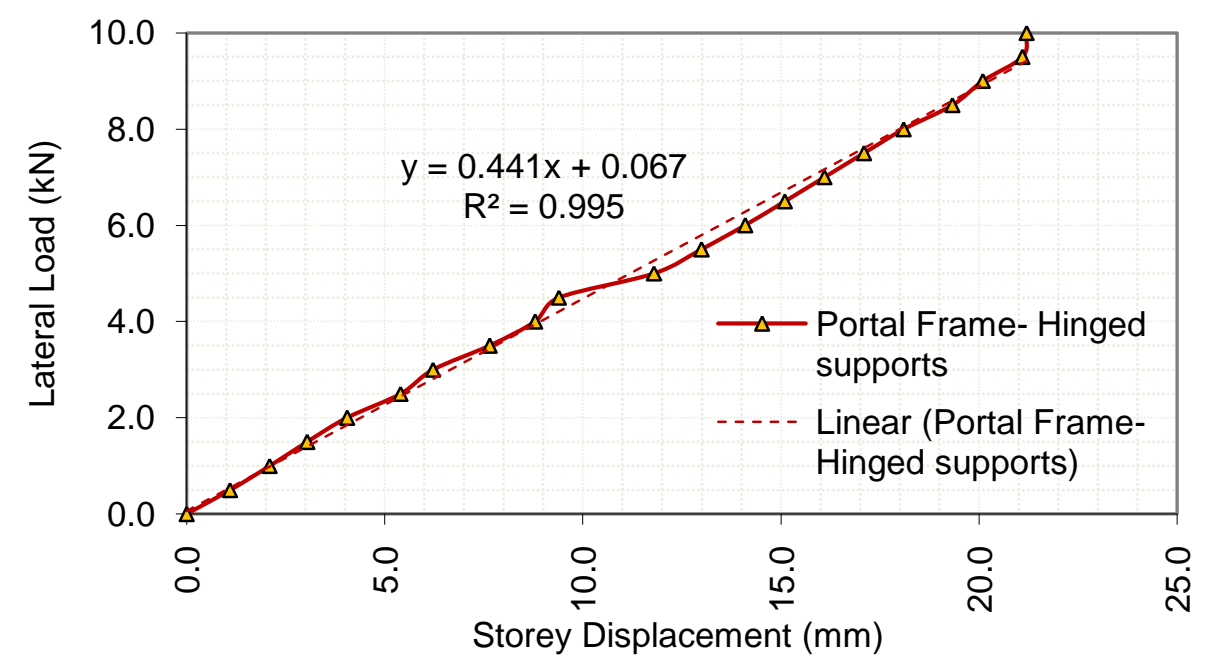

Fig. 8: Load-deflection (storey level) response for portal frames with hinged supports

The successive deflection patterns are drawn in Figures 9 and 10 for portal frames with fixed supports and hinged supports respectively. The increase in rotational capacity of the frame with hinges is prominently observed.

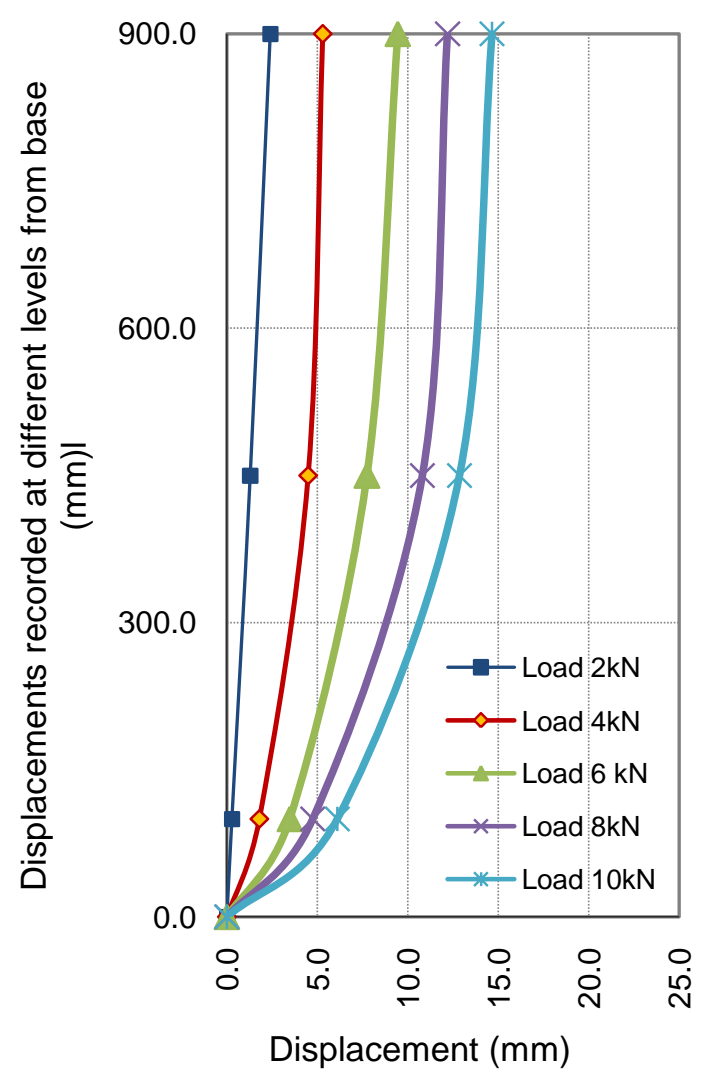

Fig. 9: Successive displacement patterns of portal frame with fixed supports

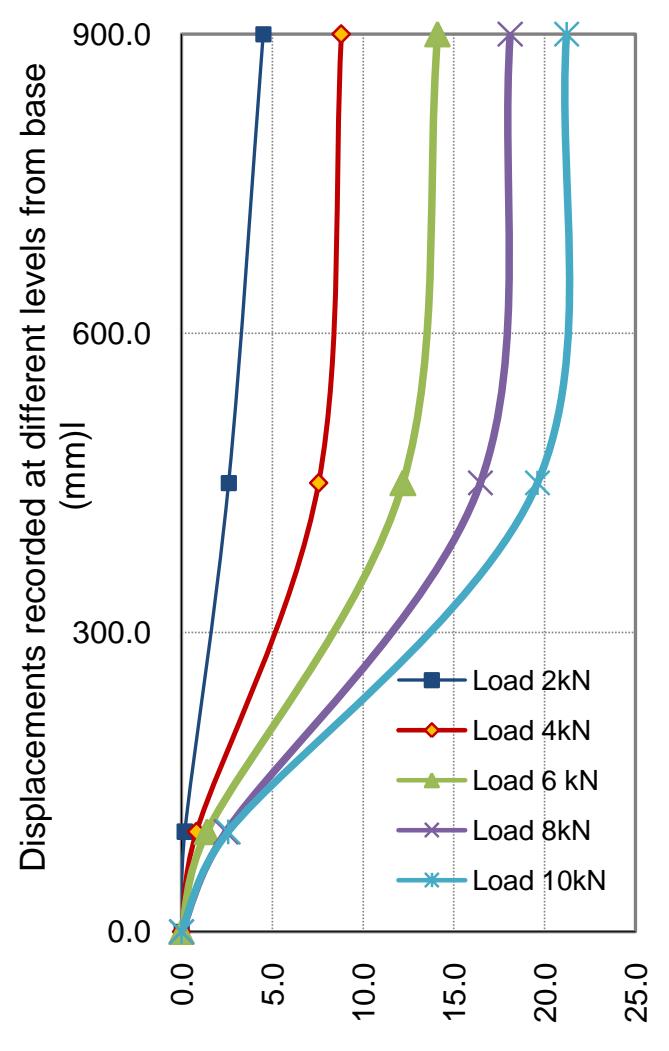

Displacement $(\mathrm{mm})$

Fig. 10: Successive displacement patterns of portal frame with hinged supports 


\section{Ductility}

The energy absorbed by the structure is a measure of its ductility. It is directly related to the area of P- $\Delta$ plots in Figures 7 and 8 . The calculation of the area under the curve is done by using the linear correlation of the best fit curve as given in the figures. The area under the curve for portal frame with fixed supports is about $73.5 \mathrm{kNmm}$ and that for the frame with hinged supports is about 105 $\mathrm{kNmm}$. It indicates an increase of about $40 \%$ in its ductility when RCC hinges were introduced.

\section{Cracking pattern}

During application of the horizontal load it was observed that the frame with fixed support started cracking at $4 \mathrm{kN}$ near the support at bottom of Column CD as shown in Figure 11(a) as the support sections are subjected to maximum bending moment.

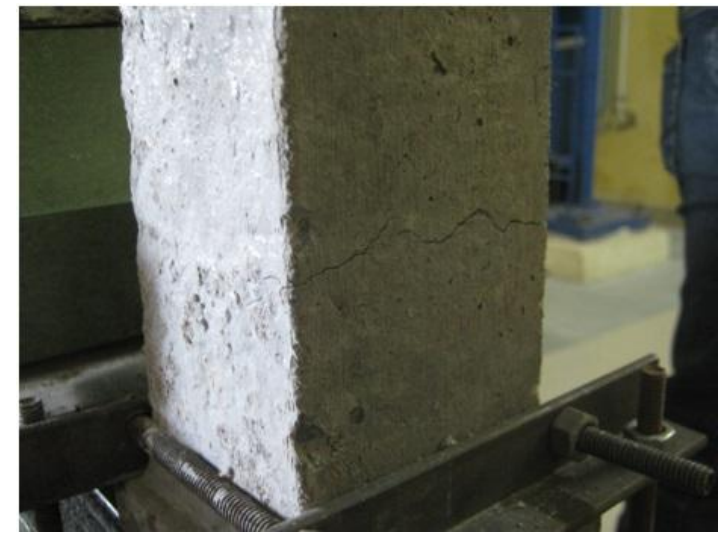

(a)Cracking at bottom of Column CD in Portal frame with fixed supports

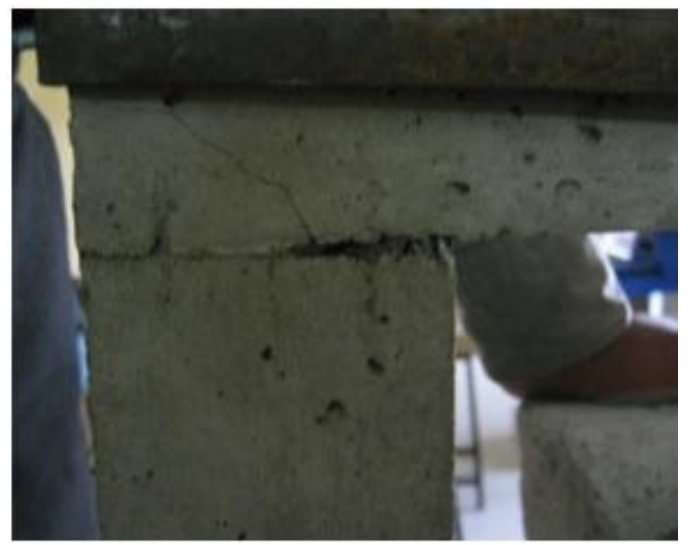

(b)Cracking at Joint C of Portal frame with hinged supports

Fig. 11: Cracking pattern

In case of portal frame with hinged supports, the cracking started at $10 \mathrm{kN}$. The cracking initiated at the joint $\mathrm{C}$ of beam BC and column CD as shown in Figure 11(b). In case of the hinged portal frame, the bending moment is the maximum at the column and beam junction.

\section{CONCLUDING REMARKS}

The effectiveness of RCC hinge was clearly and convincingly observed. The storey displacements and ductility of the portal frame were increased by introducing hinges at the supports. The pushover analysis of the portal frames showed the enhanced behaviour by introduction of RCC hinges. The increased ductility can be effectively utilized during the lateral loadings during earthquakes. Desired ductility for a building frame can be achieved by introducing a number of hinges at the interface of column base and footing and its structural analysis is suggested to identify the proper locations and number of hinges to be provided.

\section{REFERENCES}

1) Mashaly El-Sayed, El-Heweity Mohamed, AbouElfath Hamdy, Ramadan Mostafa, "A new beamcolumn model for seismic analysis of RC frames Part II: Model Verification", Alexandria Engineering Journal, 2012, 51, 53-60. (www.elsevier.com/locate/aej)

2) Dubey S. D. and Kute S. Y., "Experimental investigation on the ultimate strength of partially in-filled and steel-braced reinforced concrete frames", International Journal of Advanced Structural Engineering, 2013, 5:15.v (http://www.advancedstructeng.com/content/5/1/15 )

3) Kilar Vojko and Fajfar Peter, "Simple Push-Over Analysis of Asymmetric Buildings", Earthquake Engineering \& Structural Dynamics, February 1997.

4) IS 10262: 2009, "Indian Standard Concrete Mix Proportioning - Guidelines (First Revision)", Bureau of Indian Standards, New Delhi.

5) Shetty M. S., "Concrete Technology Theory and Practice", S. Chand and Company Ltd., New Delhi, 2005.

6) IS 456: 2000, "Indian Standard Plain and Reinforced Concrete - Code of Practice (Fourth Revision)", Bureau of Indian Standards, New Delhi.

7) Pillai S. U. and Menon D., "Reinforced Concrete Design”, McGraw Hill Education (India) Private Limited, $3^{\text {rd }}$ edition, New Delhi, 2009.

8) Punmia B. C. and Jain Ashok Kumar, Jain Arun Kumar, "Reinforced Concrete Structures", Vol. II, $5^{\text {th }}$ edition, Laxmi Publications Pvt. Ltd., New Delhi, 1992. 